Cell Research (2002); 12(3-4):257-262

http://www.cell-research.com

SHORT COMMUNICATION

\title{
A mRNA molecule encoding truncated excitatory amino acid car- rier 1 (EAAC1) protein (EAAC2) is transcribed from an indepen- dent promoter but not an alternative splicing event
}

\author{
Xiao Ping JIN, Ji Bin PENG, Fang HUANG, Ya Ni ZHU, Jian FEI*, Li He GUO* \\ Laboratory of Molecular Cell Biology, Institute of Biochemistry and Cell Biology, Shanghai Institutes for Biological \\ Sciences, Chinese Academy of Sciences, 320 Yueyang Road, Shanghai 200031, China
}

\begin{abstract}
Glutamate transporter EAAC1 removes excitatory neurotransmitter in central nervous system, and also absorbs glutamate in epithelia of intestine, kidney, liver and heart for normal cell growth. When a mouse cDNA was screened using EAAC1 cDNA fragment as probe in our lab, a transcript (GenBank U75214) encoding an EAAC1 protein with 148 residues truncated at $\mathrm{N}$-terminal was cloned and named as EAAC2. Sequence analysis shows that EAAC2 has it' s own start code and unique 5' TR that is different from that of EAAC1. A mouse genomic library was screened and a positive clone including EAAC1 CDS was sequenced (GenBank AF 322393) and indicates that normal EAAC1 transcript (GenBank U73521) is transcribed from 10 exons in terms of exon I, II, III, IV, V, VI, VII, VIII, IX, X, and EAAC2 transcript is consisted by exons from IV to IX as same as that of EAAC1 and with its unique exon $\beta$ upstream to exon IV and exon d downstream to IX. EAAC2 transcript has a cluster of transcriptional start sites not overlapping with the transcriptional start sites of EAAC1. These results indicate that EAAC2 is transcribed from an independent promoter but not an alternative splicing event.
\end{abstract}

Key words: genomic organization, glutamate transporter, transcriptional start sites EAAC1.

\section{INTRODUCTION}

Glutamate transporters are able to uptake neurotransmitter glutamate from synaptic cleft and maintain its concentration at low level $(<1 \mu \mathrm{M})$ thus to protect neurons from excitotoxicity caused by Glu [1]. Up to now, five subtypes of glutamate transporter GLAST (EAAT1)[2], GLT-1 (EAAT2)[3], EAAC1 (EAAT3)[4], EAAT4[5] and EAAT5[6] have been cloned. Excitatory amino acid carrier 1 (EAAC1) is a high-affinity $\mathrm{Na}^{+}$-dependent Lglutamate/D, L-aspartate cell-membrane transporter

\footnotetext{
* Corresponding author: To whom correspondence and reprint requests should be addressed.

E-mail: mhzhang@sunm.shcnc.ac.cn Tel: 86-21-64315030-2069

Received March-25-2002 Revised July-15-2002 Accepted July25-2002
}

protein. EAAC1 cDNA was originally cloned from rabbit small jejunum[4], followed by finding its counterparts in rat [7-9], mouse[10] and human[11-14]. Human EAAC1 gene was mapped to 9p24, which was linked to dicarboxylic aminaciduria and neurodegenerative disorders[15]. Loss of function studies by means of chronic antisense oligonucleotide administration[16] and gene knockout[17] revealed that EAAC1 deficiency did not lead to neurodegeneration, although EAAC1 was believed to be a neuronal glutamate transporter. Functional EAAC1 was assembled as pentamer in EAAC1 expressed Xenopus oocyte plasma membrane[18].

However, genomic organization of EAAC1 was not fully understood, only its partial genomic organization was documented[17]. During the experi- 
EAAC2: A mRNA molecule encoding truncated EAAC1 protein

ment of screening of mouse EAAC1 cDNA in our lab, a truncated EAAC1 transcript was cloned and named as EAAC2. In order to address the genomic organization relationship between EAAC1 and EAAC2 transcripts, we cloned the mouse genomic fragment for $\mathrm{EAAC1}$, and also identified transcriptional start sites for EAAC1 and EAAC2 by 5' RACE. We also detected their expressions at transcriptional level by RT-PCR.

\section{MATERIALS AND METHODS}

\section{Mouse EAAC1 and EAAC2 cDNA cloning}

The method for cloning EAAC1 cDNA and EAAC2 cDNA from the neonatal Balb/C mouse brain cDNA library (Stratagene Cat. No. 937301) was detailed in literature[19].

\section{Mouse genomic organization analysis}

The mouse genomic library (Stratagene Cat. No. 946309) was screened with EAAC1 full length cDNA as a probe. The positive genomic clones were mapped by suitable restriction endonucleases and subcloned. DNA sequence was analyzed by automatic fluorescent sequencer. The DNA sequence data were aligned and analyzed by GCG software package.

\section{5' RACE}

Poly A + mRNA was isolated from tissues of neonatal mice and adult mice by OligotexTM mRNA Mini Kit (Qiagen Cat. No.70022). The first-strand cDNA synthesis and 5' RACE PCR amplification were performed according to manufacturer's instructions (Clontech, Cat. No. K1811-1). For 5' RACE of EAAC1 transcript, P1 primer (All the primers sequence information were listed in Tab 1) was used as EAAC1 gene specific primer in the first round PCR, and P2 primer was used as EAAC1 nest primer in the second round PCR. For 5' RACE of EAAC2 transcript, P3 primer was used as EAAC2 gene specific primer in the first round PCR, and P4 primer was used as EAAC2 nest primer in the second round PCR. Sequences of 5' RACE PCR products were analysed directly or after T-Vector cloning by automatic fluorescent sequencer.

\section{$R T-P C R$}

Total RNA was extracted from mice tissues using Trizol reagent (Gibcol BRL), then treated with RNase-free DNase I to eliminate the contaminant of chromosomal DNA. Approximately $5 \mu \mathrm{g}$ total RNA was converted into the first-strand cDNA using Oligo dT15 as primer. The E. coli RNase H (TaKaRa) was used to remove the RNA templet. The cDNA was used as template in PCR amplification. P5 and P6 primers were used for the specific region of EAAC1 transcript and P7 and P8 primers for PCR amplification of the specific region of EAAC2 transcript. PCR amplification of GAPDH was used as reference that generated by P9 and P10 primers.

\section{RESULTS AND DISCUSSION}

\section{Characters of EAAC1 and EAAC2 transcripts}

The EAAC1 cDNA that we cloned in this paper is totally in length of $3727 \mathrm{bp}$. The sequence was deposited in GenBank (U73521). Its open reading frame from nucleotide 76 to 1648 encoded a protein of 523 residues, which was identical to the sequence of EAAC1 protein reported previously[10], except amino acid substitution of methinine at site of 141 for isoleucine. Both polyadenylation signal and translational initiation context of EAAC1 transcript were consistent with the consensus sequences. During our cloning EAAC1 cDNA, we obtained a novel cDNA clone with the insertion sequence of $2176 \mathrm{bp}$. The sequence was deposited in GenBank (U75214) and named as EAAC2. With comparison to EAAC1, EAAC2 had 288 bp specific sequence in 5' untranslated region, but its rest sequence was identical to EAAC1 except its 3' untranslated region

Tab 1. PCR primers list

\begin{tabular}{|c|c|c|}
\hline Primer & Nucleotide Sequence & GenBank and Position \\
\hline $\mathrm{P} 1$ & $5^{\prime} \quad$ AAT TCC TAG TAC CAC GGC GGC CAC G 3' & EAAC1: U73521: 172-148. \\
\hline $\mathrm{P} 2$ & 5’ CAT GGT GAG CAC TGA CGT TTG 3' & EAAC1: U73521: 79-59. \\
\hline P3 & 5' GTT CTG TTT CTC ATC TGG CGT CCG 3' & EAAC2: U75214: 196-173. \\
\hline $\mathrm{P} 4$ & 5' CAG AAG TCT TCC TCA TCA AC 3 , & EAAC2: U75214: 100-81. \\
\hline P5 & 5' GCT CGA ATT CAC CAT GGG GAA GCC CAC 3' & EAAC1: U73521: 72- \\
\hline \multicolumn{3}{|l|}{90.} \\
\hline & EcoR I & \\
\hline P6 & 5’ GGT CCA ACA TGG CAT CCA TGG 3' & EAAC1: U73521 509- \\
\hline \multicolumn{3}{|l|}{489.} \\
\hline P7 & 5’ GCA GGA CTT CCC TGA GAA CAG 3’ & EAAC2: U75214: 27-47. \\
\hline P8 & 5' TTG GAG ACA CGG AAA ACA G 3' & EAAC2: U75214: 288- 270. \\
\hline P9 & 5' ACG ACC CCT TCA TTG ACC 3 , & GAPDH: M32599: 141-159. \\
\hline P10 & 5' AGA CAC CAG TAG ACT CCA CG 3 ' & GAPDH: M32599: 345-325. \\
\hline
\end{tabular}


was shortened for $1341 \mathrm{bp}$. Its open reading frame from nucleotide 296 to 1423 encoded a protein of 375 residues, which was identical to EAAC1 protein from residue 149 to 523 with 148 residues truncated at $\mathrm{N}$-terminal. However, both polyadenylation signal and translational initiation context of EAAC2 transcript were not typical but potential.

The genomic organizations of EAAC1 and EAAC2 transcripts

To further study whether the EAAC2 is a spliced variation of EAAC1 or an independent transcript, we screened the genomic library of mice. Three posi- tive phage clones were fished out by the probe of EAAC1 cDNA. With the overlapping insertion genomic sequence of $18.2 \mathrm{~kb}, 15.2 \mathrm{~kb}$ and $16.2 \mathrm{~kb}$ respectively in these three clones, a physical map of $33 \mathrm{~kb}$ was constructed . Approximately $25 \mathrm{~kb}$ of genomic sequence from Sal I to BamH I was sequenced in order to address the genomic organization relationship between EAAC1 and EAAC2 transcripts, the sequence data of $25407 \mathrm{bp}$ was deposited in Genbank (GenBank AF322393). The genomic organizations of EAAC1 and EAAC2 transcripts were showed in Fig 1 and Tab 2.

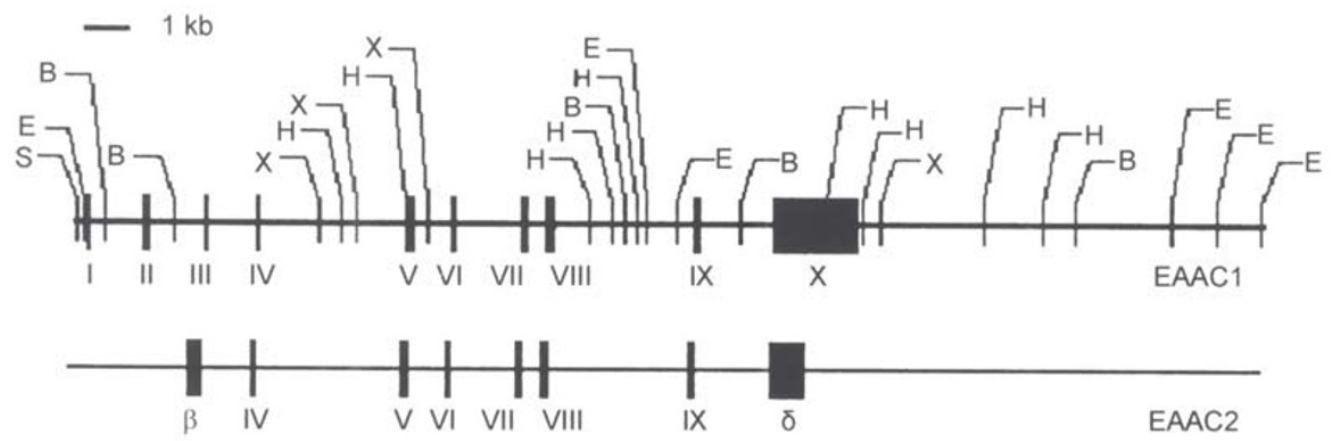

Fig 1. The genomic organizations of EAAC1 and EAAC2 transcripts

The upper line showed the physical map of mouse genomic DNA (33 kb) derived from three overlapping positive clones screened from mice genomic library. Restriction enzymes used: B: BamH I, E: EcoR I, H: Hind III, S: Sal I and X: Xba I; Solid bar: exon. EAAC1 is transcribed from exon I, II, III, IV, V, VI, VII, VIII, IX, $\mathrm{X}$ (the region from nucleotide 1 to nucleotide 308 of EAAC1 transcript is not included in this genomic sequence). EAAC2 is transcribed from exon $\beta$, IV, V, VI, VII, VIII, IX, $\delta$ and showed in the line below.

Tab 2.The genomic organizations of EAAC1 and EAAC2 transcripts

\begin{tabular}{|c|c|c|c|c|c|c|c|}
\hline Exon & $\begin{array}{l}\text { Size } \\
\text { bp }\end{array}$ & $\begin{array}{l}\text { EAAC1 } \\
\text { U73521 }\end{array}$ & $\begin{array}{l}\text { EAAC2 } \\
\text { U75214 }\end{array}$ & $\begin{array}{l}\text { Genomic } \\
\text { AF322393 }\end{array}$ & $\begin{array}{l}\text { Intron } \\
\text { Size bp }\end{array}$ & $\begin{array}{c}5 \text { ' Splice } \\
\text { site } \\
\end{array}$ & $\begin{array}{l}\text { 3' Splice } \\
\text { site }\end{array}$ \\
\hline & & & & & & & cag $\downarrow G T G T$ \\
\hline I & 92 & $309-401$ & & $277-369$ & 1531 & CTAG $\downarrow_{g t}$ & cag $\downarrow G T A T$ \\
\hline II & 114 & $402-516$ & & $1896-2010$ & 1517 & TCAG $\downarrow$ gt & cag $\downarrow G A A C$ \\
\hline $\mathrm{b}$ & 334 & & $1-334$ & $3236-3569$ & & & cag $\downarrow$ CTG \\
\hline III & 42 & $517-559$ & & $3527-3569$ & 1380 & GCAG $\downarrow_{\mathrm{gt}}$ & cag $\downarrow$ TACA \\
\hline IV & 95 & $560-655$ & $335-430$ & $4950-5045$ & 4061 & TGAG $\downarrow$ gt & cag $\downarrow A A C A$ \\
\hline V & 184 & $656-840$ & $431-615$ & 9106-9290 & 1060 & TGTG»gt & tag $\downarrow \mathrm{CTAC}$ \\
\hline VI & 107 & $841-948$ & $616-723$ & $10351-10458$ & 1827 & GCGG $\downarrow_{g t}$ & cag $\downarrow G C T T$ \\
\hline VII & 122 & $949-1071$ & $724-846$ & $12285-12407$ & 598 & CCAG»gt & cag $\downarrow$ TTCG \\
\hline VIII & 194 & $1072-1266$ & $847-1041$ & 13005-13199 & 3907 & TCAG $\downarrow$ gt & tag $\downarrow \mathrm{CATT}$ \\
\hline IX & 134 & $1267-1401$ & $1042-1176$ & $17106-17240$ & 2100 & TCCT $\downarrow$ gt & cag $\downarrow$ GGAC \\
\hline d & 969 & & $1177-2146$ & 19340-20309 & & AATGAA $\downarrow$ & \\
\hline $\mathrm{X}$ & 2282 & $1402-3684$ & & 19340-21619 & & AATAAA $\downarrow$ & \\
\hline
\end{tabular}


The region from nucleotide 309 to 3727 of EAAC1 transcript was distributed into 10 exons, in terms of exon I, II, III, IV, V, VI, VII, VIII, IX, X (Fig 1 and Tab 2). The corresponding genomic sequence from nucleotide 1 to 308 of EAAC1 transcript and its upstream regulation and control sequence were not included in this genomic sequence. All exon and intron junctions were followed the "GT-AG" rule (Tab 2)[20]. Two polyadenylation signals were located at nucleotide 21614 and nucleotide 21174 .

EAAC2 transcript was distributed into 8 exons, in terms of exon $\beta, \mathrm{IV}, \mathrm{V}, \mathrm{VI}, \mathrm{VII}, \mathrm{VIII}, \mathrm{IX}, \delta$ (Fig1 and Tab 2). Among them, exon IV, V, VI, VII, VIII, IX were identical to exons for EAAC1 transcript. Exon $\beta$ contained the 288 bp specific sequence at 5', untranslated region of EAAC2 transcript and the sequence overlapped with exon III at the 3 ' end. Exon d was identical to exon X but with 1310 bp shortened at 3 ' end. All exon and intron junctions were consistent with consensus sequence (Tab 2)[20]. There was no TATA box, CAAT box, CpG Island and octamer consensus sequences upstream from exon $\beta$. Its polyadenylation signal AATGAA at nucleotide 20309 was not typical but potential.

\section{Transcriptional start sites of EAAC1 and EAAC2} transcripts

We employed 5' RACE method to test whether the 5' sequences of EAAC1 and EAAC2 transcripts were complete, and to identify their transcription start sites. EAAC1 transcript 5' RACE product with the length of about $150 \mathrm{bp}$ was amplified from
mRNA of 24 to 36 hours postnatal mice (D1) cortex, D1 kidney, and D1 intestine, of 72 to $96 \mathrm{~h}$ postnatal mice (D3) intestine and of one year old mouse whole brain tissue (Fig 2). These sequences fully matched to EAAC1 sequence from nucleotide 1 to 79 and extended 33 bp in 5' upstream direction as following: 5. GAA T G G CA G G C T TACA G C GGCCGGTGCG CGT 3'. Since the genomic sequence corresponding the region from nucleotide1

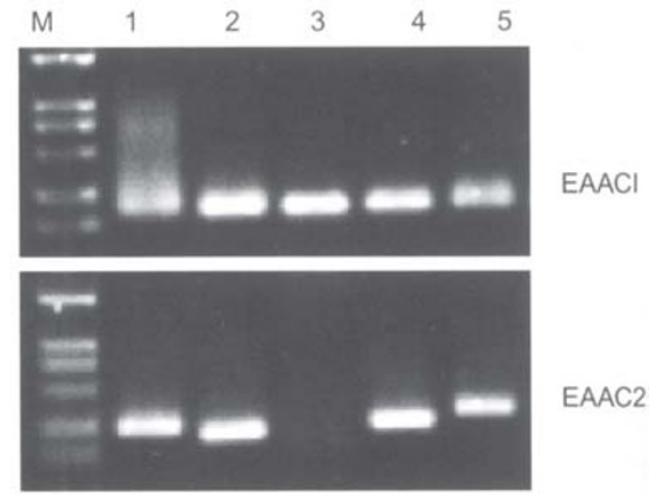

Fig 2. 5' RACE of EAAC1 and EAAC2 transcripts 5' RACE of EAAC1 transcript was done using P1 as gene specific primer for the first round PCR amplification and using P2 as nest primer for the second round PCR. 5' RACE of EAAC2 transcript was done using P3 as gene specific primer for the first round PCR amplification and using P4 as nest primer for the second round PCR. Lane M: DNA Marker (TaKaRa), $50 \mathrm{ng}$ for each band at sizes of $2000 \mathrm{bp}, 1000 \mathrm{bp}$, $750 \mathrm{bp}, 500 \mathrm{bp}, 250 \mathrm{bp}$ and $100 \mathrm{bp}$; Lane 1: D1 cerebral cortex including hippocampus; Lane 2: D1 kidney; Lane 3: D1 intestine; Lane 4: D3 intestine; Lane 5: One year old mouse whole brain.

Tab 3. 5' RACE of EAAC1and EAAC2 transcripts

\begin{tabular}{llllll}
\hline Tissue & Transcript & $\begin{array}{l}\text { Additional } \\
\text { Sequence }\end{array}$ & $\begin{array}{l}\text { Genomic } \\
\text { Site }\end{array}$ & $\begin{array}{l}\text { 5' Most } \\
\text { Genomic }\end{array}$ & $\begin{array}{l}\text { Nucleotide } \\
\text { Context }\end{array}$ \\
\hline D1 Cortex & EAAC1 & $+33 \mathrm{bp}$ & $\mathrm{n} / \mathrm{a}$ & $\mathrm{n} / \mathrm{a}$ & \\
& EAAC2 & $+89 \mathrm{bp}$ & $3147-3236$ & $3147:$ & ttt六GGG \\
D1 Kidney & EAAC1 & $+33 \mathrm{bp}$ & $\mathrm{n} / \mathrm{a}$ & $\mathrm{n} / \mathrm{a}$ & \\
& EAAC2 & $+45 \mathrm{bp}$ & $3191-3236$ & $3191:$ & gac六AGA \\
D3 Intestine & EAAC1 & $+33 \mathrm{bp}$ & $\mathrm{n} / \mathrm{a}$ & $\mathrm{n} / \mathrm{a}$ & \\
& EAAC2 & $+65 \mathrm{bp}$ & $3172-3236$ & $3172:$ & act六GGA \\
Mature Mouse & EAAC1 & $+33 \mathrm{bp}$ & $\mathrm{n} / \mathrm{a}$ & $\mathrm{n} / \mathrm{a}$ & aca \\
Brain & EAAC2 & $+120 \mathrm{bp}$ & $3116-3236$ & $3116:$ & \\
CTG & & & & & \\
\hline
\end{tabular}

Note: $\mathrm{n} / \mathrm{a}=$ not available 
to 308 of EAAC1 transcript did not locate in our genomic sequence, we were not able to analyze the transcriptional start sites of EAAC1 transcript. The fact that both additional sequence and additional length (Tab 3) were identical in all products from different source indicated that EAAC1 transcript was transcribed from a unique transcriptional start site.

The DNA fragments of 5' RACE of EAAC2 transcript were in the length of $200 \mathrm{bp}$ to $300 \mathrm{bp}$ from the mRNA of D1 cerebral cortex, D1 kidney, D3 intestine and one year old mouse whole brain (Fig 2). Sequence analysis showed that they were perfectly identical to not only nucleotide 1 to 100 of EAAC2 transcript, but also the genomic sequence in consecutive. The additional length of EAAC2 5' RACE product in 5' upstream direction was $89 \mathrm{bp}$ in the mRNA of D1 cerebral cortex, $45 \mathrm{bp}$ in D1 kidney, 65 bp in D3 intestine and 120 bp in oneyear-old mouse whole brain (Tab 3 ). The genomic contexts surrounding the 5' first nucleotides in EAAC2 5' RACE additional sequences were not consistent with splicing consensus sequences [20], which indicated that EAAC2 transcript was not the product of alternative splicing and supported that EAAC2 was initiated at different transcriptional start sites to that of EAAC1 in tested tissues. Combining of the result of genomic organization analysis, it does not seem that the transcript of EAAC1 and EAAC2 are created by the same promoter from different transcriptional start sites. We believe that the EAAC2 transcription is initiated from an independent promoter different from that of EAAC1.

\section{Expressions of EAAC1 and EAAC2 transcripts at transcriptional level}

RT-PCR with EAAC1 and EAAC2 5' specific primers indicated that both EAAC1 and EAAC2 were expressed in cerebral cortex, hippocampus, cerebellum, brain stem, lung and kidney tissues of D3 neonatal mouse (Fig 3).

In this paper we reported a new cDNA clone (EAAC2) encoding a N-terminal truncated EAAC1 protein was found. We also proved that EAAC2 transcription was initiated from its own promoter other than an alternative splicing of EAAC1. The expression pattern of EAAC2 is nearly identical in spatiotemporal manner to that of EAAC1. We expressed EAAC2 cDNA in Xenopus oocyte by infecting cDNA of EAAC2 to measure if it could be Glu transporter, the answer was no (data not shown). We also coexpressed EAAC1 and EAAC2 in oocyte to see if EAAC2 had effect on the function of EAAC1, but no effect of EAAC2 was found on the function of EAAC1 (data not shown). To address the question that what is the biological function of EAAC2 is a big challenge to our further work.

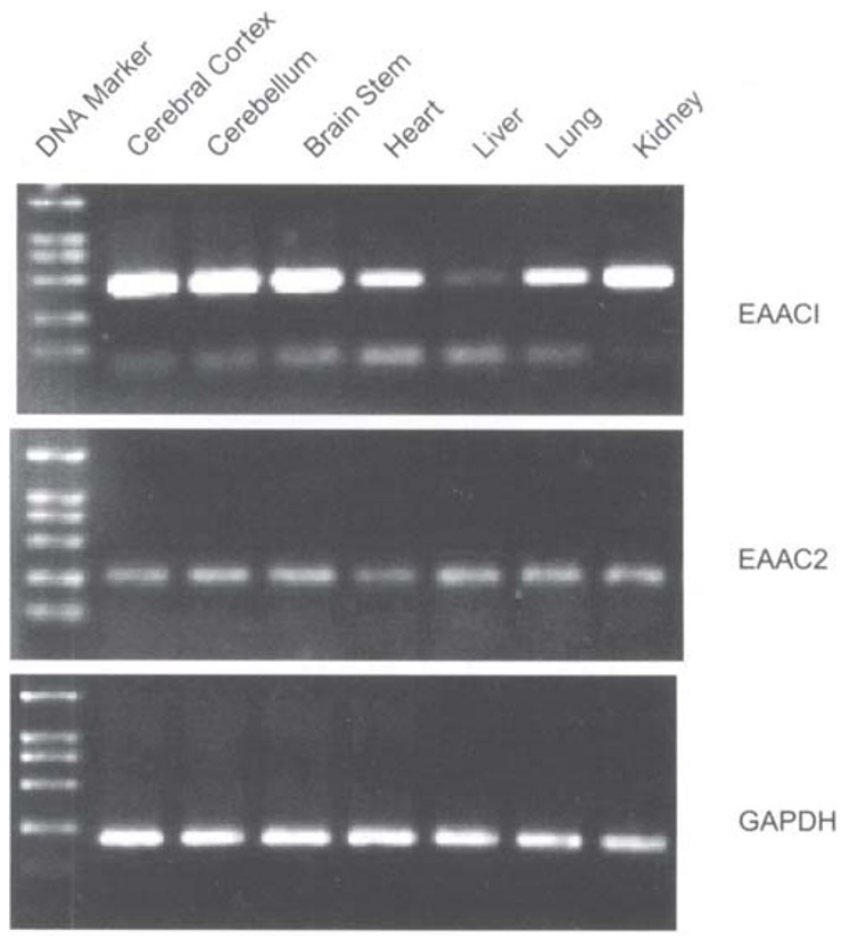

Fig 3. RT-PCR detections of EAAC1 and EAAC2 expression

EAAC1 5' specific sequence was amplified by PCR using P5 and $\mathrm{P} 6$ as primers. EAAC2 5' specific sequence was amplified by PCR using P7 and P8 as primers. House keeping gene GAPDH was amplified by PCR using P9 and P10 primers as positive control. The sample was collected from cerebral cortex including hippocampus, cerebellum, brain stem, heart, liver, lung and kidney of neonatal mice within 72 to 96 hours after postnatal (D3).

\section{ACKNOWLEDGEMENTS}

This research was supported by foundations from Chinese Academy of Sciences and Special Funds for Major State Basic Research of China (G19990539).

\section{REFERENCES}

[1] Kanai Y. Family of neutral and acidic amino acid transporters: molecular biology, physiology and medical implications. Curr Opin Cell Biol 1997; 9:565-72. 
[2] Storck T, Schulte S, Hofmann K, Stoffel W. Structure, expression, and functional analysis of a $\mathrm{Na}(+)$-dependent glutamate/aspartate transporter from rat brain. Proc Natl Acad Sci USA 1992; 89:10955-9.

[3] Pines G, Danbolt NC, Bjoras M, Zhang Y, Bendahan A, Eide L, et al. Cloning and expression of a rat brain Lglutamate transporter [published erratum appears in Nature 1992 Dec 24-31;360(6406):768] [see comments]. Nature 1992; 360:464-7.

[4] Kanai Y, Hediger MA. Primary structure and functional characterization of a high-affinity glutamate transporter [see comments]. Nature 1992; 360:467-71.

[5] Fairman WA, Vandenberg RJ, Arriza JL, Kavanaugh MP, Amara SG. An excitatory amino-acid transporter with properties of a ligand-gated chloride channel. Nature 1995; 375:599-603.

[6] Arriza JL, Eliasof S, Kavanaugh MP, Amara SG. Excitatory amino acid transporter 5 , a retinal glutamate transporter coupled to a chloride conductance. Proc Natl Acad Sci USA 1997; 94:4155-60.

[7]Bjoras M, Gjesdal O, Erickson JD, Torp R, Levy LM, Ottersen OP, et al. Cloning and expression of a neuronal rat brain glutamate transporter. Brain Res Mol Brain Res 1996; 36:163-8.

[8] Kiryu S, Yao GL, Morita N, Kato H, Kiyama H. Nerve injury enhances rat neuronal glutamate transporter expression: identification by differential display PCR. J Neurosci 1995; 15:7872-8.

[9] Velaz FM, McGraw TS, alandro MS, Fremeau-RT J, Kilberg MS, Anderson KJ. Characterization and distribution of the neuronal glutamate transporter EAAC1 in rat brain. Am J Physiol 1996; 270:C67-C75.

[10] Mukainaka Y, Tanaka K, Hagiwara T, Wada K. Molecular cloning of two glutamate transporter subtypes from mouse brain. Biochim Biophys Acta 1995; 1244:233-37.

[11] Arriza JL, Fairman WA, Wadiche JI, Murdoch GH, Kavanaugh MP, Amara SG. Functional comparisons of three glutamate transporter subtypes cloned from human motor cortex. J Neurosci 1994; 14:5559-69.

[12] Kanai Y, Stelzner M, Nussberger S, Khawaja S, Hebert
SC, Smith CP, et al. The neuronal and epithelial human high affinity glutamate transporter. Insights into structure and mechanism of transport. J Biol Chem 1994; 269:20599-606.

[13]Kanai Y, Nussberger S, Romero MF, Boron WF, Hebert SC, Hediger MA. Electrogenic properties of the epithelial and neuronal high affinity glutamate transporter. J Biol Chem 1995; 270:16561-68.

[14] Shashidharan P, Huntley GW, Meyer T, Morrison JH, Plaitakis A. Neuron-specific human glutamate transporter: molecular cloning, characterization and expression in human brain. Brain Res 1994; 662:245-50.

[15] Smith CP, Weremowicz S, Kanai Y, Stelzner M, Morton CC, Hediger MA. Assignment of the gene coding for the human high-affinity glutamate transporter EAAC1 to 9p24: potential role in dicarboxylic aminoaciduria and neurodegenerative disorders. Genomics 1994; 20:3356.

[16] Rothstein JD, Dykes HM, Pardo CA, Bristol LA, Jin L, Kuncl RW, et al. Knockout of glutamate transporters reveals a major role for astroglial transport in excitotoxicity and clearance of glutamate. Neuron 1996; 16:675-86.

[17] Peghini P, Janzen J, Stoffel W. Glutamate transporter EAAC-1-deficient mice develop dicarboxylic aminoaciduria and behavioral abnormalities but no neurodegeneration. EMBO J 1997; 16:3822-32.

[18] Eskandari S, Kreman M, Kavanaugh MP, Wright EM, Zampighi GA. Pentameric assembly of a neuronal glutamate transporter. Proc Natl Acad Sci USA 2000; 97:8641-46.

[19] Peng Jibing, Fei Jian, Huang Fang, Jin Xiaoping, Gu Quanbao, Guo Lihe. Cloning and Analyzing of Members of Excitatory Amino Acid Transporter Family From Neonatal Mouse Brain. Acta Biologiae Experimentalis Sinica 2000; 33(1):53-62.

[20] Breathnach R, Chambon P. Organization and expression of eucaryotic split genes coding for proteins. Annu Rev Biochem 1981; 50:349-83. 